\title{
Spontaneous rupture of the esophagus: report of two cases
}

\author{
Serviço de Cirurgia de Tórax do Hospital do Servidor Público Estadual - São Paulo, Brazil
}

\begin{abstract}
Objective - To study the diagnosis, prognosis and management of spontaneous rupture of the esophagus. Design: This is a retrospective study through the analysis of two cases with delayed diagnosis and subsequent treatment at the Track Surgery Service. Locale: The study was performed at the Thoracic Surgery Unit of the Hospital do Servidor Público Estadual Francisco Morato de Oliveira in the city of São Paulo. This is a specialized service. Participants: The two patients reported on had suffered spontaneous rupture of the esophagus. They were transferred to the Thoracic Surgery Unit because of the worsening of their condition in the previous institution which they had been admitted into. Measurement: The two patients with esophagus pleural fistula received similar treatment, initially advocated by Kanashin in Russia and Hauer-Santos in the United States, which consists of washing the fistula and using continuous pleural aspiration. Results: Although both patients had to spend a long period of time in hospital, their evolution was satisfactory with the treatment adopted, and the fistula closed. Conclusion: The authors conclude that the method of lavage of the mediastinum and continuous pleural aspiration, in patients who after spontaneous rupture of the esophagus developed a pleural esophagus fistula due to belated diagnosis, is an alternative and satisfactory therapy. Furthermore, in order to have the best outcome, an early diagnosis is recommended and thoracostomy as the surgical procedure, with primary suture.
\end{abstract}

UNITERMS: Boerhaave Syndrome. Spontaneous rupture of the esophagus. Post-emetic rupture of the esophagus. Esophageal pleural fistula.

\section{INTRODUCTION}

$\mathrm{S}$ pontaneous rupture of the esophagus was first reported in 1784 by Hermann Boerhaave.' This professor of medicine at Leyden was called to attend to Baron Johann Van Wassenaer - Great Admiral of the Dutch Fleet - who presented a severe gastric disorder after having taken part in a banquet.

To ease the Baron's malaise Boerhaave gave him an emetic. The Baron, after forceful vomiting, had severe pains in the chest. His clinical condition quickly worsened and he himself stated that the upper part of his stomach had ruptured and that, given the intensity of pain his demise was unavoidable. The Baron's prognosis was correct: he died 18 hours later. The autopsy, performed by Boerhaave himself, disclosed an ulceration on the distal third of the esophagus and food residues in the pleural cavity.

Although the Boerhaave Syndrome is quite rare, it cannot be forgotten in the presence of a severe pain in the chest after a sudden increase of intraesophageal pressure, as is the case in the vomiting mechanism.

To delay diagnosis and treatment will lead to a high rate of morbidity and mortality.

The two cases managed recently at our Thoracic Surgery Unit describe the severity of this syndrome.

\section{CASE 1}

A.T.S.F., male, Caucasian, 52 years of age, was admitted into the Emergency Ward of the hospital at 9.00 am on October, 15, 1994, coming from the southern coastal region of the State. 
He reported that at 2:00 p.m. of the previous day, after having ingested a large amount of food and alcoholic beverages, he presented intense vomiting and, afterwards a severe pain in the chest.

He was taken to the local hospital where, in spite of analgesics administered, pain was not suppressed, and upon worsening of the clinical picture he was transferred to São Paulo.

At the admissional examination, the patient presented tachypnea and tachycardia (f $24 \mathrm{pm}$, FC $96 \mathrm{pm}$, AP $11 \times 7)$. He had an emphysema in the left supraclavicular compartment. A reduced vesicular murmur in the left hemithorax was noted at auscultation.

A gasometry was taken and indicated normal. The blood test measured $\mathrm{Hb} 14 \mathrm{~g} / \%$; Htc 44; GB: 3,500 with a deflection to the left.

Simple X-ray of the chest in anteroposterior position showed a hazy shadow on the left hemithorax.

One of the hypotheses was that of esophagic rupture, and an endoscopy was immediately requested which confirmed a laceration in the left distal third with presence of food residues.

The patient was immediately forwarded to the Surgery Room and submitted to a left posterolateral thoracostomy. Inventory of the cavity disclosed $300 \mathrm{ml}$ of yellowish fluid with debris of fibrin. However, the mediastinum pleura presented intact, with outpouching, swollen and covered by fibrin. It was opened and let out a large quantity of food residues, that once removed disclosed a posterolateral esophagic laceration, extending for about $6 \mathrm{~cm}$ from the cardia.

After cleaning of the site, the lesion was closed with four simple cotton 4.0 sutures on a single plane, essentially intended to orient cicatrization along the suture line, as

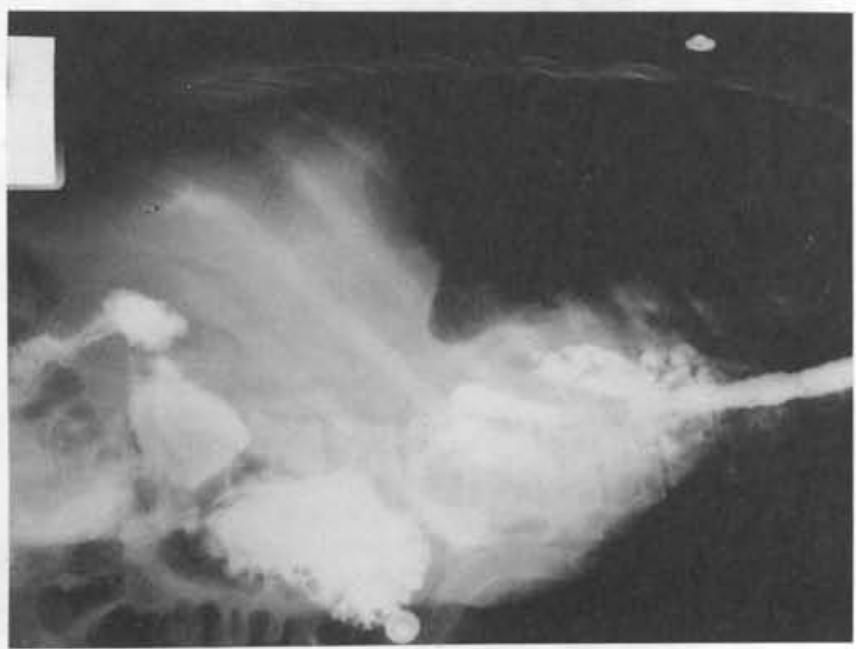

Figure 1 - Esophagram of patient A.T.S.F on 6 th P.O.

Note the extravasation in the mediastinum contrast and in the pleural cavity due to suture dehiscence. the wound was potentially infected. The pleural cavity was washed and a multiperforated drain was attached to the rib-vertebrae gutter, next to the lesion. After this, the patient was sent to the ICU.

On the fifth P.O. an esophagogram was performed, using Iodate contrast, which disclosed an esophageal fistula in the distal esophagus.

Although the patient was not unstable, at this moment he presented pleural-esophageal fistula and bilateral empyema (Fig. 2), bearing evidence of severe mediastinal infection.

The chosen treatment was that proposed by HauerSantos (2) which consists of an enteral probe, with its distal end close to the fistula, infusing physiological saline solution to which was added a chloranphenicol solution.

The pleural drainage tube was kept under continuous suction, allowing for constant removal of the washout of the whole infected area.

Simultaneously a jejunostomy was performed to maintain the nutritional condition.

The patient presented progressive improvement.

On November 22, he was submitted to another esophagogram which disclosed closure of the fistula (Fig. 4).

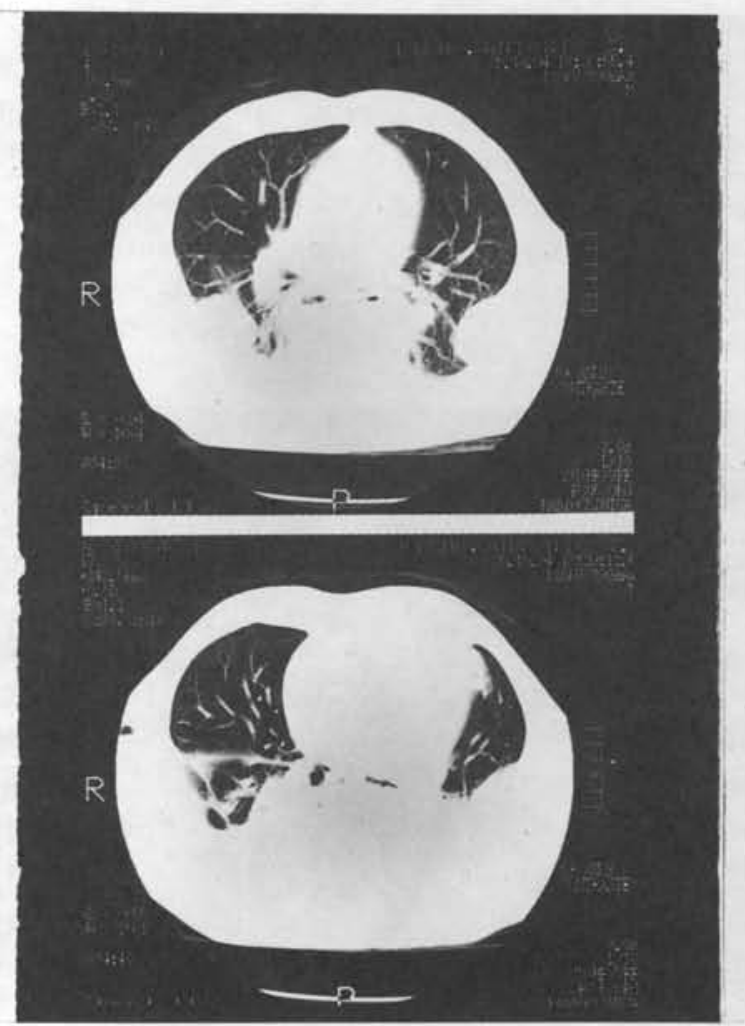

Figure 2-Computerized tomography of the thorax of patient A.T.S. $\mathrm{F}$ on the 14th P.O. Note the bilateral pleural effusion (emphyema) as a consequence of the mediastinitis. 
He was released on December, 9, 1994, in good physical condition. His clinical and radiological pulmonary condition was practically normal (Fig. 5).

\section{CASE 2}

H.B. 68 years old, male, Adventist, was admitted on June 10,1994, mentioning that on the day before, after an abundant meal he had forceful vomiting, followed by severe retrosternal pain spreading out to the back. He went to an emergency day-care ward where an angina pectoris or a myocardial infarction were suspected, although not confirmed, after which the patient was dismissed.

Because of the persistent and increasingly severe pains, he came to the Emergency Attendance of the Hospital. A chest $\mathrm{X}$-ray disclosed an effusion in the pleura on the right side with characteristics of posterior sepsis. An esophageal rupture was suspected: an esophagoscopy was requested, which confirmed a tear of about $4 \mathrm{~cm}$ at the distal third. The patient was then submitted to surgery, pharyngostomy, block of distal transit with a Foley probe, pleural drainage on the right side and jejunostomy for parenteral nutrition.

This treatment was continued for 20 days. There was, however, a progressive worsening of the overall condition with an intense toxemic picture, and it was decided to perform a thoracostomy, debridement of the pleural space and drainage of the mediastinum. A wide-bore pleural drainage tube was introduced near to the esophageal fistula under continuous

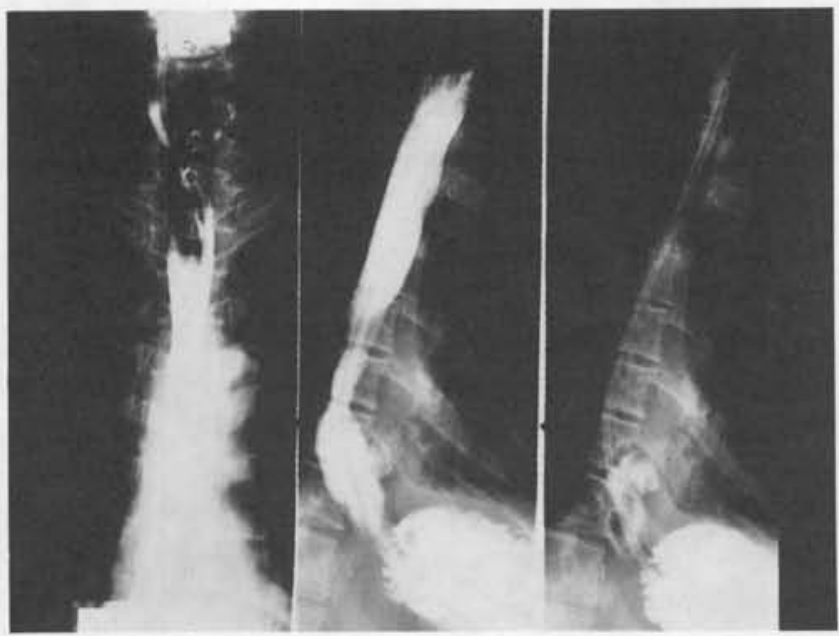

Figure 3 - Patient A.T.S.F. on the 15th P.O. Thoracic drainage with continuous aspiration, enteral probe for washing out of fistula and jejunotomy.

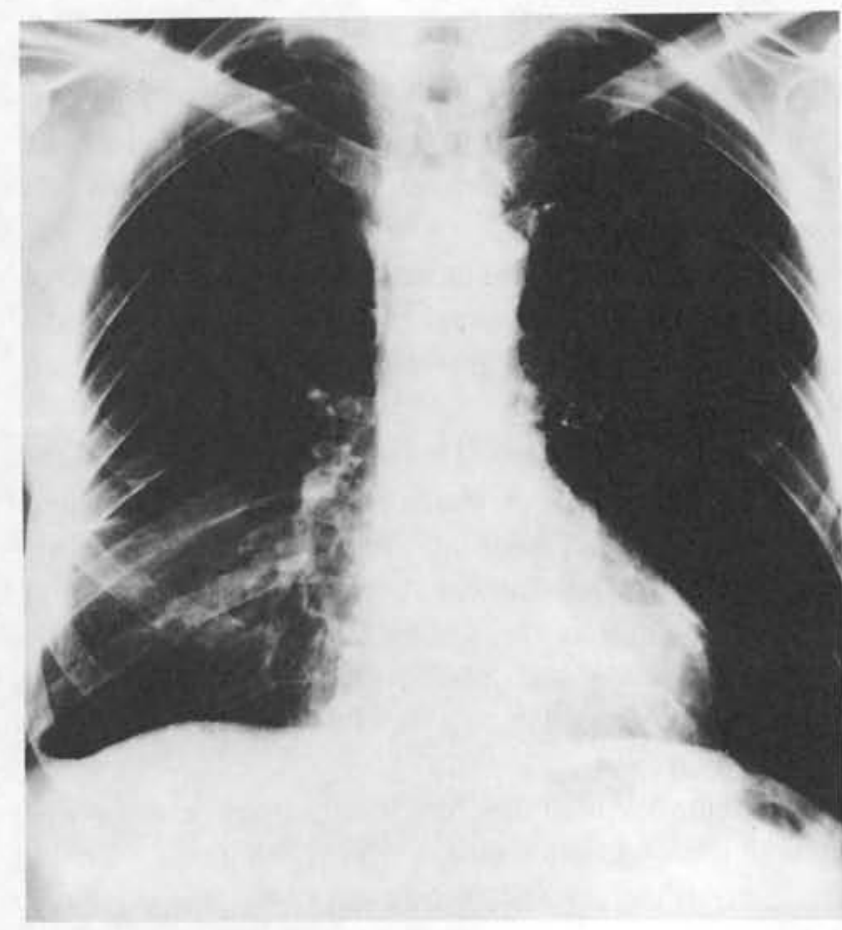

Figure 4 - Esophagram of patient A.T.S.F. on the 28th. P.O. There is no contrast overflowing. Fistula is closed.

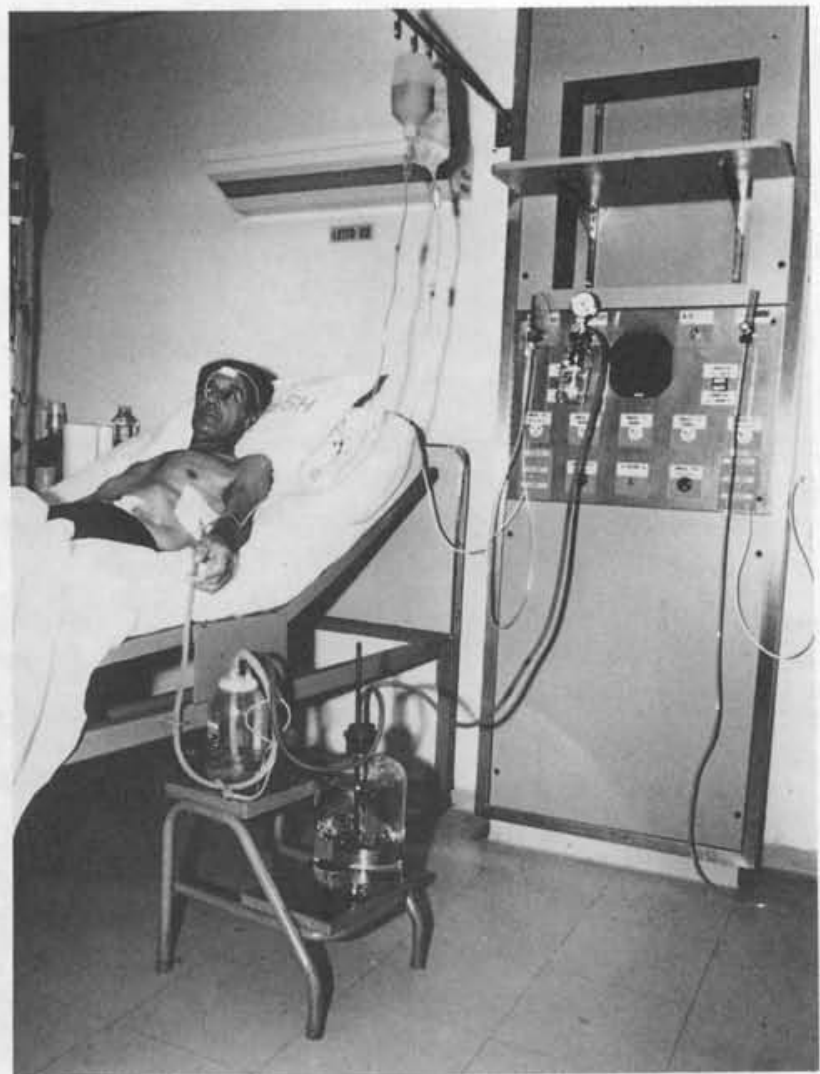

Figure 5 - Plain X-ray of thorax of patient A.T.S.F. on the 30th P.O. after fistula had closed. Almost full resolvability of the bilateral emphyema. 
aspiration. The margins of the scar were brought together by four stitches of non absorbable sutures to orient cicatrization.

The Foley probe was introduced again, roughly over the position of the fistula, for infusion of the physiological saline solution.

As after 10 days the washing out liquid was still purulent, chloranphenicol was added to the physiological saline solution $(1 \mathrm{~g} / 1,000 \mathrm{ml})$ dripping into the vein at $120 \mathrm{ml} /$ hour.

After another ten days, the clinical picture had improved with a significant reduction of output deposits in the collecting bottle, showing a preferential flow to the stomach. An endoscopy undertaken at that time, evinced that the fistula had been reduced from 4 to $1.2 \mathrm{~cm}$.

Treatment was continued for another 18 days and a new endoscopic examination disclosed an even greater reduction of the fistula's size, now down to $0.2 \mathrm{~cm}$. On the 30 th day of treatment the fistula was fully closed.

\section{DISCUSSION}

Spontaneous rupture of the esophagus consists of the full rupture of a segment of its wall, as a result of a sudden increase of the endo-luminal pressure. The other causes of rupture, such as those provoked by surgical instrumentation or perforating wounds on the chest would be excluded by definition.

Post-prandial vomiting has been most frequently held responsible for this rupture, but nevertheless, the literature also mentions other ruling factors for the rapid increase of abdominal pressure such as coughing, labor and defecation. ${ }^{3,45}$

Currently, it is believed that the most likely mechanism involved is a malfunction of the overall vomiting reflex. The coordinated relaxation of the cricopharyngeal muscles will not take place, bringing about a high pressure chamber inside its lumen, mainly in the distal third where rupture usually takes place.

Mostly, the rupture is located in the left posterolateral compartment of the esophagus, next to the cardia, and can reach up to $6 \mathrm{~cm}$ in length. ${ }^{3.4}$

Occurrence of laceration in this site has been attributed, among other anatomical causes, to the entrance of vessels and nerves, to the angulation of the organ and to the absence of supportive tissue. ${ }^{4}$ According to Faber, ${ }^{6}$ the sudden increase of pressure would be an even more significant factor than the rate of increase itself.

Of the damages caused to the esophagus by such mechanisms, complete rupture or Boerhaave Syndrome is the most dramatic, although some of lesser severity have been described.

Mallory \& Weiss, in $1929,{ }^{7}$ reported a gastrointestinal bleeding associated with vomiting. The anatomopathological substrate consisted of shreds of the mucosa in the proximity of the cardia.

Williams in $1957,{ }^{8}$ reported intramural dissection of post-emetic cause that did not lead to total rupture of the esophagean wall, forming a hematoma within the muscle bundles (Fig. 6).

Until the mid-19th Century, the Boerhaave Syndrome was exclusively a finding at autopsies. In 1858, Mayer ${ }^{9}$ would have been the first to reach a diagnosis prior to death.

Derbes \& Mitchell $^{4}$ attribute the first surgical treatment to Overholt in the United States, in 1943. However, it was Barrett in England, in $1947,{ }^{10}$ who first published a paper on the therapeutical success of a surgical approach.

Boerhaave Syndrome has a higher incidence in the male gender, at an average of 50 years of age."

Its predisposing factors would be alcoholism, a neurological disease, a peptic ulcer, a hiatal hernia or arterial hypertension. ${ }^{12}$ However, many sick individuals do not present any of these disorders. The classic clinical triad includes: vomiting, pain in the chest and subcutaneous emphysema. ${ }^{13}$

Other abnormalities exhibiting pain in the chest or the upper abdomen and vomiting may be confounded with the syndrome; among them, we can consider myocardiac ischemia, perforated peptic ulcer and acute pancreatitis, dissecting aortal aneurysm and aspiration pneumonia.

$\mathrm{X}$-rays are an essential tool for correct diagnosis. Chest $\mathrm{x}$-rays may show widening and emphysema of the mediastinum, hidrothorax, pneumothorax and lung condensations. Naclerio ${ }^{14}$ described the "V" sign which consists of an irregular increase in pulmonary density on the left side of the cardiac contour, stressing chemical pneumonia next to the esophageal area. To ascertain the presence of a rupture, swallowing Iodate contrast will show the effusion. In case of doubt an endoscopic examination will confirm the hypothesis.

Barrett ${ }^{12,10}$ after his experience with the first case of surgical treatment by primary suture of the tear, claimed that only surgery would guarantee the patient's survival.

However, it has been observed that, to obtain positive results in this type of treatment, an early diagnosis is required. Its delay dramatically increases mortality rates. According to some authors, ${ }^{15,16}$ after the first 24 hours, this rate would range from $20 \%$ to $50 \%$. Tissue friability, as a result of necrotizing enzymes and infectious agents, would hamper cicatrization. 


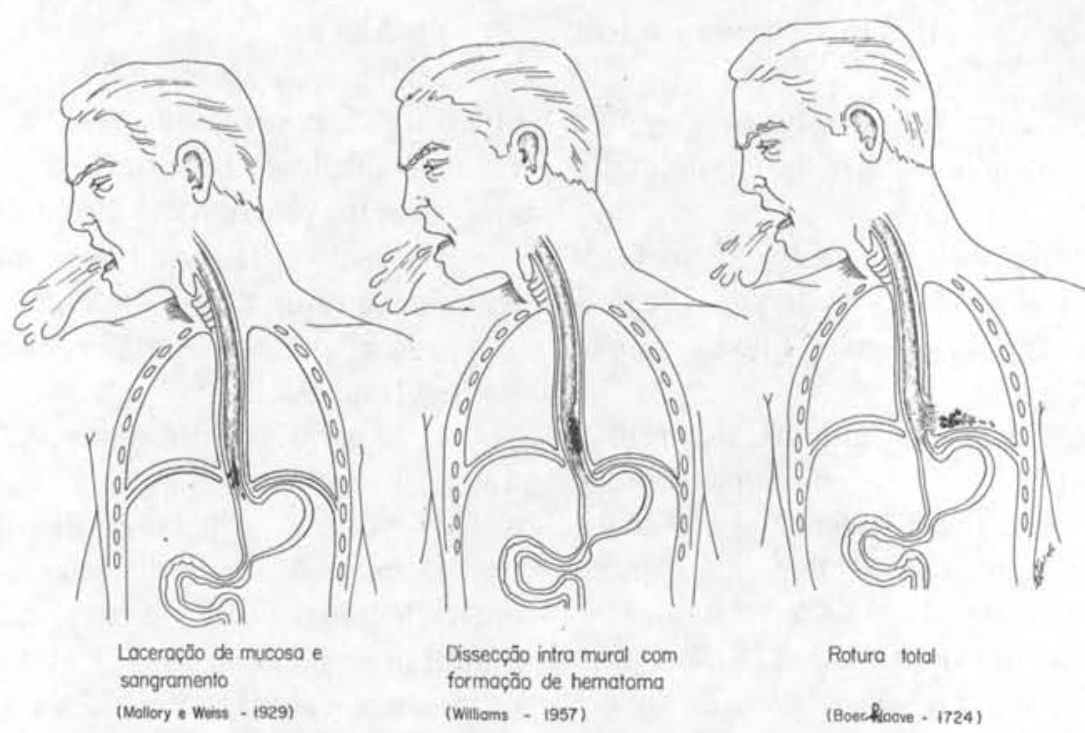

Figure 6 - Esophageal lesions due to intramural pressure increase. (Post Emetic) Laceration of mucosa and intramural dissection with total rupture bleeding hematoma (Mallory \& Weiss - 1929) (Williams - 1957) (Boerhaave - 1724)

However, in medical literature there has been no agreement regarding the time span for the performance of the primary suture. According to Samson ${ }^{17}$ the maximum delay for a rhaphy could not be for more than 15 hours.

In view of the above statements, various more complex procedures have been described intending to reduce the possibility of dehiscence: repairs of sutures with synthetic flaps ${ }^{3}$ or with live tissues, such as the intercostal pedicle ${ }^{18}$ of the pericardium, ${ }^{19}$ of the pleura, ${ }^{20}$ as well as protection of the gastric stump. ${ }^{21}$

Johnson, Schenegran \& Kimby ${ }^{15}$ recommended the functional exclusion of the esophagus through a cervicostomy and ligature of the distal sphincter. More drastic surgeries, including esophagostomy ${ }^{22}$ were also recommended.

Nevertheless, so far no conclusion has been reached about how beneficial for the severely impaired patient those major surgical procedures indeed are.

The essential management for rupture of the esophagus consists of reversal of the chain of events triggered by the entrance of bacteria and active chemical matter inside the mediastinum, that may lead to an uncontrollable sepsis. ${ }^{23}$ As infection is not controllable, the laceration will not close.

A therapeutic approach, with continuous lavage of the rupture site, initially described in Russian literature ${ }^{24}$ ${ }^{26}$ was accepted by other authors ${ }^{2,27}$ as a rather efficient therapy for the closure of the fistula. The ongoing removal of the necrotic matter and of the bacterial constituent using physiological saline solution and

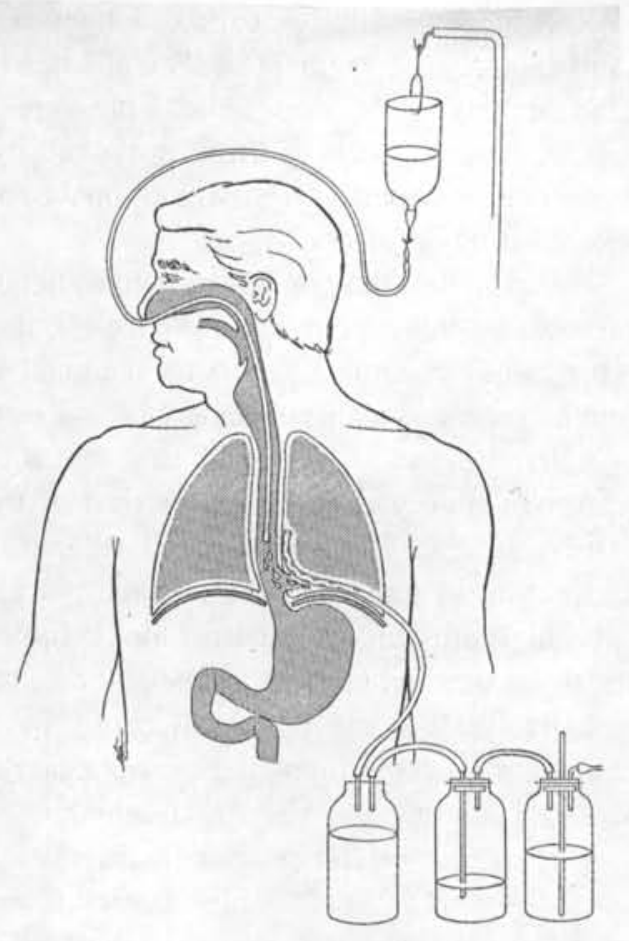

Figure 7 - Treatment of esophagus rupture by washing out of fistula. An enteral probe is located a little above the site of rupture, continually instilling physiological saline solution with antibiotics. A multiopening pleural drainage tube is fixed next to the fistula with constant aspiration. 
continued suction, evinced positive results in ruptures at all esophageal levels.

In our service, we have therefore systematized the procedures for the spontaneous rupture of the esophagus: thoracotomy, cleansing of the site, suture of the laceration (even many hours after the rupture), drainage of the cavity, and parenteral nutrition by jejunostomy. Should cicatrization not be successful, the pleuralesophagic fistula will be treated according to the work of Hauer Santos ${ }^{2}$ :

1. Placing of a nasogastric probe (Dobbhoff) a little above the fistula;

2. Transpleural drainage of the mediastinum by a wide gauge drain, multiperforated and attached next to the fistula;
3. Continuous dripping of physiologic serum with chloranphenicol $(1 \mathrm{~g} / 1000 \mathrm{ml})$ at a $120 \mathrm{ml} /$ hour rate;

4. Continuous aspiration of the pleural cavity at a pressure of $25 \mathrm{~mm} / \mathrm{h} 20$ (Fig. 7).

This procedure aims to avoid that the contaminated matter of the oropharynx, the active enzymes and the necrotic tissue retain mediastinal infection, which would deter closing of the fistula.

The final objective of these two reports is to enhance surgeons' awareness of the need for immediate repair of the lesion and, should an early diagnosis not have been reached, introduce a simple alternative treatment with a positive outcome.

\section{Resumo}

Objetivo: Estudar o diagnóstico, prognóstico e manejo da ruptura espontânea do esôfago. Desenho: Este é um estudo através de dois casos com diagnóstico demorado e subseqüente no Serviço de Cirurgia. Local: este estudo foi realizado na Unidade de Cirurgia Torácica do Hospital do Servidor Público Estadual Francisco Morato de Oliveira na cidade de São Paulo. Participantes: os dois pacientes aqui relatados sofreram ruptura espontânea do esôfago. Estes pacientes haviam sido transferidos para a Unidade de Cirurgia Torácica devido à piora da condição clínica na instituição em que haviam sido anteriormente admitidos. Mensuração: os dois pacientes com fístula esôfago-pleural receberam tratamento semelhante, inicialmente proposto por Kanashin na Rússia e por Hauer-Santos nos Estados Unidos. Este tratamento consiste em lavagem da fístula com aspiraçāo contínua. Resultados: embora ambos os pacientes tenham passado um longo período no hospital, a evolução foi satisfatória com o tratamento adotado e a fístula fechou. Conclusão: os autores concluem que o método de lavagem do mediastino e a respiraçāo pleural contínua é uma alternativa satisfatória em pacientes que sofreram ruptura espontânea do esôfago e desenvolveram fístula devido à demora no diagnóstico. Além disso, a fim de obter o melhor resultado, o diagnóstico precoce é necessário e recomenda-se a toracotomia como procedimento cirúrgico, com sutura primária.

\section{REFERENCES}

1. Boerhaave H. Atrocis nec descriotu prius morbi historia. The first translation of the classic case report of the rupture of the esophagus with annotation. Bull Med Lib Assoc $1955 ; 43: 217-240$.

2. Santos GH, Frater RWN. Transesophagical irrigation for the treatment of mediastinitis produced by esophageal rupture. J Thoracic Cardiovasc Surg 1986; 91:57-9.

3. Abbott, OA, Mansur, KA, Logan WD. A traumatic so called "spontaneous rupture of the esophagus". A review of 47 personal cases with comments on a new method of surgical therapy. J Thorac Cardiovasc Surg 1970; 59:67-83.

4. Derbes VH, Mitchell RE. Rupture of the esophagus. Surgery 1956;39:688-709.

5. Verwoerd CA, Van Mazkm F, Meyer JM A conservative approach in selected cases of late diagnosed oesophageal rupture. Thorax 1977; 32:232-4.
6. Faber HI. Spontaneous rupture of the normal oesophagus 1962; 25:93-98.

7. Mallory GK, Weiss S. Hemorrhages from laceration of the cardiac orifice of the stomach due to vomiting . Am J Med Sci 1929; 178:506-15.

8. Williams B. Oesophageal laceration following remote trauma. Br J Radiol 1957; 30:666-8.

9. Meyer J. Med bg Brlu 1858; I, 201.

10. Barrett, NR. Report of case of spontaneous rupture of oesophagus successfully treated by operation. Br J Surg 1947; 35: 216-20

11. Bennett DJ, Deveridje RJ, Wright JS. Spontaneous rupture of the esophagus. A review with report of six cases. Surgery $1970 ; 68: 766-770$.

12. Barrett, NR. Spontaneous rupture of the oesophagus. Thorax 1946; 1: 48-70.

13. Walker WS, Cameron EWJ, Walbaum PR Diagnosis and management of spontaneous transmural rupture of the esophagus (Boerhaave's Syndrome) Br J Surg 1985; 72: 204-7. 
14. Naclerio EA. The "V-sign" in the diagnosis of spontaneous rupture of the esophagus. Am J Surg 1957; 93: 291-298.

15. Johnson J, Schwegmann CW, Kirby CK. Esophageal exclusion for persistent fistula following spontaneous rupture of the oesophagus. JThoracic Surg 1956; 32:827-32.

16. Sandrasagra FA, English TAH, Milstein BB. Prognosis and management of Boerhaave's Syndrome (proceedings of the thoracic and cardiovasc surg) Thorax 1978; 33:131.

17. Samson PE. Post-emetic rupture of the esophagus Surg Gynec Obst 1951; 93:221-25.

18. Lester RB, Eiseman B. Experimental evaluation of intercostal pedicle in esophageal repair. J Thoracic Cardiovasc Surg 1965; 50:626-31.

19. Millard AH. Spontaneous rupture of the oesophagus treated by utilization of a pericardial graff. Br J Surg 1971; 58:70-2.

20. Michel L, Grillo HC, Malt RA. Esophageal rupture. Ann Thorac Surg 1982; 33:203-10.
21. Thal, AP, Hatafuku T. Improved operation for esophageal rupture. JAMA 1964;188: 126-28

22. Urscgel HC, Razuk MA, Wood RE, Galbrath W, Paulson D. Improvement management of oesophageal rupture. Thorax 1977; 32:232-4.

23. Payne WS, Larson RH. Acute mediastinitis. Surg Clin North Am 1969; 49: 99-110.

24. Kanaschin NN, Abukamov MM, Scherbatenko MK. The prophylaxis and treatment of purulent mediastinitis. Vestin Khir 1973; 99: 103-7.

25. Kanaschin NN, Pogodina AN. Transesophageal drainage of the mediastinum in mediastinitis. Vestin Khir 1983; 30:24-6.

26. Komaroc BD, Kanaschin NN, Abumakov A, Pogodina AN. Diagnosis and treatment of purulent mediastinitis. Khirurgia (Mosk) 1982;4:33-8.

27. Santos GH, Shapiro M, Komsar. A Role of transoral irrigation in mediastinitis due to hipopharingeal rupture. Head \& Neck Surgery 1986; 9:116-21. 